\title{
Assessing the effects of different agro-residue as substrates on growth cycle and yield of Grifola frondosa and statistical optimization of substrate components using simplex-lattice design
}

Bing Song ${ }^{1 \dagger}$, Jianqiang $\mathrm{Ye}^{1,2+}$, Frederick Leo Sossah ${ }^{1 \dagger}$, Changtian $\mathrm{Li}^{1}$, Dan Li $\mathrm{i}^{1}$, Lingsi Meng ${ }^{1}$, Shuai Xu ${ }^{1}$, Yongping $\mathrm{Fu}^{1 *}$ and $\mathrm{Yu} \mathrm{Li}^{1 *}$

\begin{abstract}
Grifola frondosa is an economically important edible and medicinal mushroom usually produced on substrate consisting of sawdust supplemented with wheat bran. Cultivation of G. frondosa on crop straw (corn cob, corn straw, rice straw, and soybean straw) as a substrate was optimized by using the D-optimum method of the simplex-lattice design, and the alternative of crop straw as a substitute for sawdust in the substrate composition was determined by the optimized model. The results showed that there was a significant positive correlation existing between the yield and corn cob. The growth cycle was negatively correlated with sawdust, corn cob and soybean straw, with sawdust significantly shortening the growth cycle of $\mathrm{G}$. frondosa. The optimized high-yielding formula included $73.125 \%$ corn cob, 1.875\% rice straw, $23 \%$ wheat bran and $2 \%$ light calcium carbonate $\left(\mathrm{CaCO}_{3}\right)(\mathrm{C} / \mathrm{N}=48.40)$. The average yield of the first flush was $134.72 \pm 4.24 \mathrm{~g} / \mathrm{bag}$, which was increased by $39.97 \%$ compared with the control formula. The biological efficiency (BE) was $44.91 \pm 1.41 \%$, which was increased by $38.53 \%$ compared with the control. Based on the results of this study, corn cob can replace sawdust as one of the main cultivation substrates of G. frondosa.
\end{abstract}

Keywords: Grifola frondosa, Crop straw, Simplex-lattice design, Yield and growth cycle, High-yielding formula, Biological efficiency

\section{Introduction}

Grifola frondosa (Dicks.) Gray, named "Maitake" in Japan, is a rare edible and medicinal fungi mainly cultivated in China, Japan and Korea (Park et al. 2015). It has a high nutritional composition with compounds such as polysaccharides, proteins, unsaturated fatty acids, vitamins, and trace elements (Gu et al. 2007; Illana-Esteban 2008; Montoya et al. 2012). It also has a wide range of bioactive

\footnotetext{
*Correspondence: yongping.fu@jlau.edu.cn; fungi966@126.com ${ }^{\dagger}$ Bing Song, Jianqiang Ye and Frederick Leo Sossah contributed equally to this work

${ }^{1}$ Engineering Research Centre of Chinese Ministry of Education for Edible and Medicinal Fungi, Jilin Agricultural University, Changchun 130118, People's Republic of China

Full list of author information is available at the end of the article
}

compounds (Shin and Lee 2014) which has been reported to have hypoglycaemic effects, anti-cancer properties, antiviral properties, antioxidant effects, immunomodulatory effects, anti-inflammatory activities, anti-cholesterol or cholesterol-lowering effects, as well as the ability to reduce blood pressure and protect the liver (Vetvicka and Vetvickova 2014; Ding et al. 2016; Lin et al. 2016). Due to the unique properties of $G$. frondosa, it has become a regular healthy food for consumption with a high demand in many countries such as the USA, Canada, Australia and some countries in Europe (Mayell 2001). The commercial profitability of this mushroom has significantly increased, necessitating a rapid expansion in its cultivation in China and other parts of the world. 
Grifola frondosa is a wood-rot fungus, which grows on standing and dead wood. It acquires nutrients for growth and development by the degradation of lignocellulosic materials (Montoya et al. 2012; Yang et al. 2013a). Conventional cultivation is on deciduous hardwood sawdust or a mixture of assorted sawdust and cottonseed hulls (Ainsworth et al. 2008). However, recent efforts concerning the protection of forest resources, together with the high demand and rising price of both sawdust and cottonseed hulls have posed a challenge to commercial cultivation of $G$. frondosa using sawdust.

It is therefore important to find the above substrate alternatives that are equally suitable and cost-effective for the commercial production of G. frondosa. Currently, large tonnages of unexploited lignocellulosic agro-residues are available globally. For example, in China agro-residues are abandoned to decay in the field and sometimes disposed of through mass burning which is a major cause of air pollution in China (Yang et al. 2012; Hu et al. 2017; Teng et al. 2017). Utilization of these by-products as substrates for cultivating mushrooms will offer one of the best solutions for converting these inedible organic wastes into important edible biomass. At present, corn straw, soybean straw, rice straw and corn cobs are widely used in the cultivation of edible mushrooms, including Lentinula edodes, Pleurotus ostreatus and Pleurotus eryngii (Moonmoon et al. 2010; Yang et al. 2013b; Hoa et al. 2015; Pedri et al. 2015). Few studies exist where straw or straw mixtures were used as the cultivation substrates of G. frondosa; also only coffee grounds (Barreto et al. 2008) and olive oil residues (Gregori et al. 2009) have been reported as substrates for G. frondosa. But these two substrates are subject to the restrictions of the place of production and thus have not made gains in promotion and application. Also, these substrates are extremely variable and traditional techniques often do not guarantee a standardized product.

Mushroom growers commonly add different ratios of natural nutrient sources from corn meal, wheat bran and rice bran to sawdust to enhance $G$. frondosa colonization and formation of superior quality fruiting body (Montoya et al. 2012). In order to produce consistent high yield and maintain/increase profitability, a commercial grower must determine the processing conditions. These conditions include quality spawn, temperature, humidity and consider the addition of an additive that is readily available, cheap and proven to increase yield and produce high quality G. frondosa in a short period of time (Montoya et al. 2012; Kraisit et al. 2017). Mixture design is one of the most widely used methods for screening formulas (the sum of the main ingredients is a unit, 1 or $100 \%$ ) and has been widely used in the feed, medicine and food industries (Kraisit et al. 2017; Pires et al. 2017; Saoudi et al. 2017). Among all mixture-design methods, the simplex-lattice design is the most commonly used method for substrate screening; it allows for good analysis of correlations of the different factors and the target values, and with regression analysis, the quantitative relations between the different substrates and assessment indicators can be obtained (Yang et al. 2016). The optimized formula and the impact of each substrate on the indicators can then be determined. Although some published studies (Shen and Royse 2001) have dealt with the effect of cereal agro-residue on growth and yield of G. frondosa, not much data is available on the use of statistical modelling for optimization of substrate composition to standardize yield in commercial cultivation as well as the presentation of alternatives to sawdust for sustainable production of G. frondosa.

The aim of the present study was to evaluate different agro-residues (sawdust, corn cob, rice straw, soybean straw and corn straw) as a substrate for cultivation of G. frondosa; and use simplex-lattice design method to model, optimize substrate composition and evaluate the combined effects on growth and yield of G. frondosa. Also, the agro-residue that can replace sawdust in the model for G. frondosa cultivation was investigated, thereby providing a reference for the further development and utilization of agricultural wastes.

\section{Materials and methods \\ Study area}

The study was conducted in Jilin Agricultural University, Changchun, China. The mycelial culture on potato dextrose agar slants, pre-screening of mycelial growth, and extracellular lignocellulolytic enzymes activity profiles were conducted at the Engineering Research Centre of the Chinese Ministry of Education for Edible and Medicinal Fungi, Jilin Agricultural University, Changchun, China. Whereas substrate preparation, fruiting body cultivation and optimization of fruiting body culture development were completed in the Mushroom base of Jilin Agricultural University, Changchun, China.

\section{Fungal culture and spawn preparation}

The pure culture of G. frondosa H21 (ACCC52310) used in this study was obtained from the Institute of Natural Resources and Regional Planning, Chinese Academy of Agricultural Sciences, Beijing, China. It is a mid-temperature tolerant and moderate-yielding strain. The strain $\mathrm{H} 21$ was selected because it is a stable commercial strain in Jilin Province, China and has been well studied for mycelial growth characteristics, fruiting body development, genetic distinctness and extracellular lignocellulolytic enzymes activity. Hence, the difference in growth and yield of this strain as a result of different substrates used can clearly be discriminated. The stock culture was maintained on a potato dextrose agar (PDA) slants 
and incubated for seven days at a temperature of $25{ }^{\circ} \mathrm{C}$ and cultured slants were stored at $4{ }^{\circ} \mathrm{C}$, until further use. G. frondosa liquid spawn was prepared by culturing $\left(0.5 \mathrm{~cm}^{2}\right)$ mycelial plugs in $500 \mathrm{ml}$ Erlenmeyer flasks containing $200 \mathrm{ml}$ Yeast malt broth (YM liquid medium), and incubated at $25^{\circ} \mathrm{C}$ with shaking $(120 \mathrm{rpm})$ on a rotatory shaker for 20 days. The YM liquid medium consisted of yeast extract $2.0 \mathrm{~g} / \mathrm{l}$, malt extract $20.0 \mathrm{~g} / \mathrm{l}$, corn flour $25.0 \mathrm{~g} / \mathrm{l}$, peptone $5.0 \mathrm{~g} / \mathrm{l}, \mathrm{KH}_{2} \mathrm{PO}_{4} 5.0 \mathrm{~g} / \mathrm{l}, \mathrm{MgSO}_{4} 2.5 \mathrm{~g} / \mathrm{l}$, sucrose $25.0 \mathrm{~g} / \mathrm{l}$, vitamin $\mathrm{B}_{1} 25 \mathrm{mg} / \mathrm{l}$ and nature $\mathrm{pH}$.

\section{Substrates preparation}

The various agro-residues (oak wood sawdust, corn cobs, corn straw, soybean straw and rice straw) and supplements [wheat bran and light calcium carbonate $\left(\mathrm{CaCO}_{3}\right.$, average particle size is $1-3 \mu \mathrm{m}$ )] for the cultivation of $G$. frondosa were purchased from the Mushroom base of the Jilin Agricultural University, Changchun, China. All agroresidues were chopped into pieces, dried, and ground into fine powder.

\section{Substrate formulation}

The various independent variables were first studied using one-factor-at-a-time method to determine the initial range of the variables. This was achieved by preparing the substrates from the various agro-residues components first in petri dishes consisting of single substrate component with sterilized water added to $\pm 62.5 \%$ prior to autoclaving at $121^{\circ} \mathrm{C}$ for $1 \mathrm{~h}$, allowed to cool and inoculated with $5 \mathrm{~cm}^{2}$ mycelial plug to determine the radial mycelial growth rate followed by fruiting body cultivation in bags. Based on the preliminary results the variables $\left(X_{1}=\right.$ sawdust, $X_{2}=$ corn cobs, $X_{3}=$ soybean straw, $X_{4}=$ rice straw and $X_{5}=$ corn straw) were selected for the simplex-lattice design. These were then mixed in various combinations to determine a good fruiting substrate for the cultivation of G. frondosa.

A total of 21 mixture schemes were designed, and the design details are shown in Table 1. All possible combinations (mixtures) of the proportions from this equation were used. The 21 formulae were prepared following the 21 mixture schemes listed in Table 1; with the main ingredient accounting for $75 \%$, scheme 1 is the control substrate mixture (CK) composed of $75 \%$ hardwood sawdust, $23 \%$ wheat bran and $2 \%$ light $\mathrm{CaCO}_{3}$, with water content of materials adjusted to $62.5 \%$, with $\mathrm{pH} 7$. The substituting ingredients were oak wood sawdust, corn cobs, corn straw, soybean straw and rice straw. All formulae contained $23 \%$ wheat bran, $2 \%$ light $\mathrm{CaCO}_{3}$ and $62.5 \%$ water with $\mathrm{pH} 7.0$ and environmental conditions remained constant for all. All experiments were tested in three replicates and randomized to minimize the effects of unexpected effects in the observed response.

\section{Model analysis}

The Scheffé model was fitted using a polynomial quadratic equation in order to correlate the response variable $(Y)$ to the independent variables $(X)$. The Eq. (1) is as follows:

$$
Y=\sum_{1 \leq i \leq q} \beta_{i} X_{i}+\sum_{1 \leq i<j \leq q} \beta_{i j} X_{i} X_{j}
$$

In a mixture experiment, it is not the volume of the actual amount of the single ingredient that matters, but rather its proportion in relation to other ingredients. The sum of all the ingredients is a constant total $T$, which is equal to $100 \%$ or 1 unless any constant mixture factors are present (Lundstedt et al. 1998).

Therefore, if $X_{1}, X_{2}, X_{3}, \ldots X_{i}$ denote the proportions of components of a mixture, then:

$$
S^{q-1}: \sum_{i=1}^{q} X_{i}=1,0 \leq X_{i} \leq 1, i=1,2, \ldots, q
$$

and

$$
\left.X_{1}+X_{2}+X_{3}+X_{4}+X_{5}=100 \% \text { (i.e., } 1\right)
$$

where $X_{1}$ represents sawdust, $X_{2}$ represents corn cob, $X_{3}$ represents soybean straw, $X_{4}$ represents rice straw, and $X_{5}$ represents corn straw.

\section{Optimization design}

Simplex lattice (D-Optional method) design was employed to determine the optimum mixture ratio, the number of experimental runs and the proportion of five agro-residues in each experimental run (Table 1) using the Design-Expert 8.05b software (Scheffé 1963; Yang et al. 2016).

\section{Substrate analyses}

The carbon $(\mathrm{C})$ and nitrogen $(\mathrm{N})$ contents of the various substrate mixtures were measured using the furnace (Wang et al. 2015) and the Kjeldahl method (Verma et al. 2007) respectively. The carbon to nitrogen ratio of each substrate was calculated and are shown in Table 1.

\section{Cultivation method}

For each formula, the ingredients, the wheat bran and the light $\mathrm{CaCO}_{3}$ were first mixed evenly per the respective mixture ratio scheme; water was then added to adjust the moisture content to approximately $62.5 \%$. A total of $800.0 \mathrm{~g}$ of such mixed substrates (dry material $300.0 \mathrm{~g}$ ) was used to fill a $33 \mathrm{~cm} \times 17.5 \mathrm{~cm} \times 0.05 \mathrm{~cm}$ polypropylene bag, with a $2.5 \mathrm{~cm}$ collar at the bag mouth. A columnshaped Polyvinylchloride (PVC), $2.5 \mathrm{~cm}$ in diameter and $12 \mathrm{~cm}$ in depth, was inserted into the collar to allow even distribution and colonization of the mycelia. The bags 
Table 1 Formula design of the cultivation materials and $\mathrm{C} / \mathrm{N}$

\begin{tabular}{|c|c|c|c|c|c|c|}
\hline \multirow[t]{2}{*}{ Formulas } & \multicolumn{5}{|c|}{ Substrate mixture ratio } & \multirow[t]{2}{*}{$\mathrm{C} / \mathrm{N}$} \\
\hline & $\mathrm{X}_{1}(\%)^{\mathrm{a}}$ & $X_{2}(\%)^{b}$ & $X_{3}(\%)^{c}$ & $X_{4}(\%)^{d}$ & $X_{5}(\%)^{e}$ & \\
\hline $1(\mathrm{CK})$ & 100 & 0 & 0 & 0 & 0 & 74.64 \\
\hline 2 & 0 & 100 & 0 & 0 & 0 & 48.9 \\
\hline 3 & 0 & 0 & 100 & 0 & 0 & 20.51 \\
\hline 4 & 0 & 0 & 0 & 100 & 0 & 34.88 \\
\hline 5 & 0 & 0 & 0 & 0 & 100 & 32.25 \\
\hline 6 & 50 & 50 & 0 & 0 & 0 & 59.12 \\
\hline 7 & 50 & 0 & 50 & 0 & 0 & 31.83 \\
\hline 8 & 50 & 0 & 0 & 50 & 0 & 47.22 \\
\hline 9 & 50 & 0 & 0 & 0 & 50 & 44.24 \\
\hline 10 & 0 & 50 & 50 & 0 & 0 & 28.65 \\
\hline 11 & 0 & 50 & 0 & 50 & 0 & 40.58 \\
\hline 12 & 0 & 50 & 0 & 0 & 50 & 38.49 \\
\hline 13 & 0 & 0 & 50 & 50 & 0 & 26.71 \\
\hline 14 & 0 & 0 & 50 & 0 & 50 & 25.22 \\
\hline 15 & 0 & 0 & 0 & 50 & 50 & 33.48 \\
\hline 16 & 60 & 10 & 10 & 10 & 10 & 47.66 \\
\hline 17 & 10 & 60 & 10 & 10 & 10 & 40.6 \\
\hline 18 & 10 & 10 & 60 & 10 & 10 & 25.82 \\
\hline 19 & 10 & 10 & 10 & 60 & 10 & 34.88 \\
\hline 20 & 10 & 10 & 10 & 10 & 60 & 33.48 \\
\hline 21 & 20 & 20 & 20 & 20 & 20 & 14.9 \\
\hline
\end{tabular}

$\mathrm{X}_{1}$-sawdust

b $\mathrm{X}_{2}$-corn cob

c $\mathrm{X}_{3}$-soybean straw

d $X_{4}$-rice straw

e $X_{5}$-corn straw

were heat sterilized by autoclaving at a temperature of $121{ }^{\circ} \mathrm{C}$ for $85 \mathrm{~min}$ and then cooled to room temperature. Further, each cooled bag was inoculated with $10 \mathrm{ml}$ liquid spawn of G. frondosa. Upon inoculation, incubation occurred at $23-26{ }^{\circ} \mathrm{C}$, the carbon dioxide $\left(\mathrm{CO}_{2}\right)$ concentration at $<3000 \mathrm{ppm}$ and in darkness, until the formation of primordia. Next, the breathable cover (diameter: $38 \mathrm{~mm}$ ) was removed, and the bag was transferred to a fruiting chamber where temperature was maintained at $19-21{ }^{\circ} \mathrm{C}$, the humidity at $93-97 \%$, the carbon dioxide $\left(\mathrm{CO}_{2}\right)$ concentration at $400-700 \mathrm{ppm}$ and the light at $200 \mathrm{l} \times / 12 \mathrm{~h}$. After fruiting harvest, the yield of each bag was recorded (only the first flush); 10 bags from each mixture scheme were used for statistical analysis.

\section{Data collection}

Data collected include growth cycle (time of inoculation to the first harvest of the fruiting body), growth parameters (length and width of a single fruiting body using a Vernier caliper), Yield parameters including total fresh weight (g) of mushroom and number of fruiting bodies per bunch were also recorded at harvest time. The BE was calculated as follows:

$$
B E(\%)=\frac{\text { Fresh weight of mushroom }}{\text { Dryweight of substrate }} \times 100
$$

\section{Statistical analysis}

The inoculated bags were arranged in complete randomized block design comprising of each treatment in the growth room. All experiments were in three replicates. Design Expert statistical software package version 8.05 b was used for regression analysis. The Scheffé quadratic polynomial regression model was used to perform a quadratic multiple regression fitting of the yield per bag and the growth cycle against the formula ingredients, and a quadratic regression model of the yield and growth cycle was constructed against each ingredient in the mixture scheme. The effects of each ingredient on the yield and on the growth cycle were analyzed, and the correlations between each ingredient and the yield and between each ingredient and the growth cycle were analyzed by SPSS Statistics 17. The optimization function was used to 
set the variation range and the expected response value of each ingredient. Beginning with a random combination, the steepest slope prediction was performed until the target response value was reached. The optimized yield formula derived from the regression analysis was verified, and ANOVA analysis was performed to estimate statistical parameters using SPSS (Yang et al. 2016).

\section{Results}

\section{Effects of different straw formulations on yield}

By statistical analysis of the yield for each formula (Table 2), the regression model equation between the yield and each ingredient was developed as follows:

$$
\begin{aligned}
Y= & 96.97 X_{1}+133.95 X_{2}+87.31 X_{3}+31.60 X_{4}+78.08 X_{5} \\
& +14.76 X_{1} X_{2}+16.90 X_{1} X_{3}-102.94 X_{1} X_{4}-2.17 X_{1} X_{5} \\
& -18.16 X_{2} X_{3}+110.01 X_{2} X_{4}+44.18 X_{2} X_{5}+29.74 X_{3} X_{4} \\
& +73.71 X_{3} X_{5}-217.52 X_{4} X_{5}\left(R^{2}=0.9956\right) .
\end{aligned}
$$

With the regression model, the predicted yield can be calculated for each formula, and the measured yield and the predicted yield were basically the same. The statistical analysis showed that the $P$ values of the mixed linear model and the quadratic regression model were both less than 0.0001 , indicating that these two models were very significant $(P<0.0001)$ and well fitted the relationship between ingredients and yield. In addition, the correlation coefficient $\left(R^{2}=0.9956\right)$ indicated that the equation model had $99.56 \%$ goodness-of-fit with the experimental data (Tables 2 and 3).

The coefficients of the independent variables in the equation reflect the degree of influence of the independent variable in the equation, i.e. the degree of contribution.

\begin{tabular}{|c|c|c|c|c|c|}
\hline $\begin{array}{l}\text { Variation } \\
\text { sources }\end{array}$ & $\begin{array}{l}\text { Sum } \\
\text { of squares }\end{array}$ & DF & Mean square & $\mathbf{F}$ & $\mathbf{P}$ \\
\hline Model & $3,760,676$ & 14 & 2686.20 & 397.07 & $<0.0001$ \\
\hline $\begin{array}{l}\text { Linear mixed } \\
\text { model }\end{array}$ & $29,142.60$ & 4 & 7285.65 & 1076.96 & $<0.0001$ \\
\hline$X_{1} X_{2}^{a}$ & 14.08 & 1 & 14.08 & 2.08 & 0.0079 \\
\hline$x_{1} x_{3}$ & 18.01 & 1 & 18.01 & 2.66 & 0.0027 \\
\hline$X_{1} X_{4}$ & 918.75 & 1 & 918.75 & 135.81 & $<0.0001$ \\
\hline$x_{1} X_{5}$ & 1.54 & 1 & 1.54 & 0.23 & 0.6823 \\
\hline$x_{2} x_{3}$ & 34.34 & 1 & 34.34 & 5.08 & 0.0014 \\
\hline$X_{2} X_{4}$ & 972.00 & 1 & 972.00 & 143.68 & $<0.0001$ \\
\hline$X_{2} X_{5}$ & 147.70 & 1 & 147.70 & 21.83 & $<0.0001$ \\
\hline$X_{3} X_{4}$ & 62.11 & 1 & 62.11 & 9.18 & $<0.0001$ \\
\hline$X_{3} X_{5}$ & 422.45 & 1 & 422.45 & 62.45 & $<0.0001$ \\
\hline$X_{4} X_{5}$ & 4029.67 & 1 & 4029.67 & 595.66 & $<0.0001$ \\
\hline Residual & 128.86 & 36 & 3.58 & & \\
\hline Lack of fit & 27.38 & 6 & 4.56 & 1.35 & 0.2669 \\
\hline Error & 101.48 & 30 & 3.38 & & \\
\hline Sum & $37,708.24$ & 29 & & & \\
\hline
\end{tabular}
As seen in the regression model, the equation coefficients
Table 3 Variance analysis of the quadratic polynomial regression model for yield

a Notes are the same as Table 1

$K\left(X_{2}\right)=133.95>K\left(X_{1}\right)=96.97>K\left(X_{3}\right)=87.31>$ $K\left(X_{5}\right)=78.08>K\left(X_{4}\right)=31.60$, which indicate that the degree of contribution of each ingredient to the yield is as follows: $X_{2}$ (corn cob) $>X_{1}$ ( sawdust) $>X_{3}$ (soybean straw) $>\mathrm{X}_{5}$ (corn straw) $>\mathrm{X}_{4}$ (rice straw). This result indicated that corncobs have the greatest degree of contribution to the yield of $G$. frondosa and can replace sawdust to serve as the main cultivation substrate of G. fron-

\begin{tabular}{|c|c|c|c|c|c|}
\hline \multirow[t]{2}{*}{ Formulas $^{1}$} & \multicolumn{2}{|l|}{ Yield (g) } & \multirow[t]{2}{*}{ Formulas } & \multicolumn{2}{|l|}{ Yield (g) } \\
\hline & Measured value ${ }^{2}$ & Predicted value & & Measured value & Predicted value \\
\hline $1(\mathrm{CK})$ & $97.25 \pm 9.71^{\text {def }}$ & 96.97 & 12 & $116.75 \pm 7.57^{\mathrm{bc}}$ & 117.06 \\
\hline 2 & $134.25 \pm 14.59^{\mathrm{a}}$ & 133.95 & 13 & $66.40 \pm 10.56^{h}$ & 66.89 \\
\hline 3 & $87.40 \pm 12.36^{\mathrm{fg}}$ & 87.31 & 14 & $100.6 \pm 9.15^{\text {de }}$ & 101.12 \\
\hline 4 & $31.75 \pm 3.61^{\mathrm{i}}$ & 31.60 & 15 & $0.00 \pm 0.00^{j}$ & 0.46 \\
\hline 5 & $78.20 \pm 20.00^{g h}$ & 78.08 & 16 & $86.65 \pm 10.00^{f g}$ & 87.09 \\
\hline 6 & $119.00 \pm 17.45^{b}$ & 119.15 & 17 & $116.00 \pm 8.00^{b c}$ & 116.79 \\
\hline 7 & $96.00 \pm 8.75^{\mathrm{ef}}$ & 96.37 & 18 & $93.50 \pm 9.50^{f}$ & 91.04 \\
\hline 8 & $38.25 \pm 2.56^{i}$ & 38.55 & 19 & $50.50 \pm 10.05^{\mathrm{hi}}$ & 49.04 \\
\hline 9 & $86.65 \pm 12.98^{f g}$ & 86.99 & 20 & $78.20 \pm 11.5^{9}$ & 76.23 \\
\hline 10 & $105.75 \pm 18.15^{\text {cde }}$ & 106.09 & 21 & $86.65 \pm 12.5^{\mathrm{fg}}$ & 83.52 \\
\hline 11 & $110.00 \pm 11.41^{\mathrm{bcd}}$ & 110.27 & & & \\
\hline
\end{tabular}
dosa. The Pearson correlation coefficients between each of the substrates and the yield determined by the SPSS

Table 2 Measured values and predicted values of yield

\footnotetext{
${ }^{1}$ Notes are the same as Table 1

${ }^{2}$ Means followed by the same letter are not significantly different at a level of $5 \%(P<0.05)$
} 
software were as follows: corn cob $(0.665)>$ soybean straw $(0.112)>$ sawdust $\quad(0.084)>$ corn straw $\quad(-0.145)>$ rice straw $(-0.706)$. The yield was positively correlated with sawdust, corn cob and soybean straw, among which a significantly positive correlation existed between the yield and corn cob. However, yield was negatively correlated with the rice straw and corn straw, among which a significantly negative correlation existed between the yield and rice straw. The details can be seen in Table 4 .

The coefficients of the mixed schemes in the equation indicate the degree of influence of the different substrate combinations on the yield. The results showed that

$$
\begin{aligned}
K\left(X_{2} X_{4}\right) & =110.01>K\left(X_{3} X_{5}\right)=73.71>K\left(X_{2} X_{5}\right) \\
& =44.18>K\left(X_{3} X_{4}\right)=29.74>K\left(X_{1} X_{3}\right) \\
& =16.90>K\left(X_{1} X_{2}\right)=14.76>K\left(X_{1} X_{5}\right) \\
& =-2.17>K\left(X_{2} X_{3}\right)=-18.16>K\left(X_{1} X_{4}\right) \\
& =-102.94>K\left(X_{4} X_{5}\right)=-217.52 .
\end{aligned}
$$

Accordingly, the degree of contribution was as follows: $\mathrm{X}_{2} \mathrm{X}_{4}$ (corn cob and rice straw) $>\mathrm{X}_{3} \mathrm{X}_{5}$ (soybean straw and corn straw) $>\mathrm{X}_{2} \mathrm{X}_{5}$ (corn cob and corn straw) $>\mathrm{X}_{3} \mathrm{X}_{4}$

Table 4 Correlation analysis between yield and the different ingredients

\begin{tabular}{llllll}
\hline & $\mathbf{X}_{\mathbf{1}}^{\mathbf{a}}$ & $\mathbf{X}_{\mathbf{2}}^{\mathbf{a}}$ & $\mathbf{X}_{\mathbf{3}}^{\mathbf{a}}$ & $\mathbf{X}_{\mathbf{4}}^{\mathbf{a}}$ & $\mathbf{X}_{\mathbf{5}}^{\mathbf{a}}$ \\
\hline Yield $^{\mathrm{b}}$ & & & & & \\
Pearson & 0.084 & $0.665^{* *}$ & 0.112 & $-0.706^{* *}$ & -0.145 \\
Significance & 0.767 & 0.008 & 0.692 & 0.003 & 0.607 \\
N & 21 & 21 & 21 & 21 & 21
\end{tabular}

a Notes are the same as Table 1

b Mean values followed by no letters are not significantly different at a level of $5 \%(P<0.05)$

** Significantly different at a level of $1 \%(P<0.01)$ (soybean straw and rice straw) $>\mathrm{X}_{1} \mathrm{X}_{3}$ (sawdust and soybean straw) $>X_{1} X_{2}$ (sawdust and corn cob) $>X_{1} X_{5}$ (sawdust and corn straw) $>\mathrm{X}_{2} \mathrm{X}_{3}$ (corn cob and soybean straw) $>\mathrm{X}_{1} \mathrm{X}_{4}$ (saw dust and rice straw) $>\mathrm{X}_{4} \mathrm{X}_{5}$ (rice straw and corn straw). Combined with the interaction analysis, mixing corn cob with sawdust, soybean straw, rice straw or corn straw significantly affected yield, and the yield increases with the corresponding increase of corn cob. Conversely, mixing rice straw with saw dust, corn cob, soybean straw or corn straw significantly reduced yield, and the yield decreases with the corresponding increase of rice straw (Table 2).

\section{Effects of different straws on the growth cycle of $G$. frondosa}

The growth cycles for each formula (Table 5), the regression model between the growth cycle and each ingredient is as follows:

$$
\begin{aligned}
Y= & 63.00 X_{1}+69.14 X_{2}+70.33 X_{3}+70.00 X_{4} \\
& +66.40 X_{5}-11.29 X_{1} X_{2}+2.58 X_{1} X_{3} \\
& +14.00 X_{1} X_{4}+5.20 X_{1} X_{5}-5.62 X_{2} X_{3} \\
& -19.88 X_{2} X_{4}-1.08 X_{2} X_{5}-24.66 X_{3} X_{4} \\
& -12.94 X_{3} X_{5}+127.20 X_{4} X_{5}\left(R^{2}=0.9652\right)
\end{aligned}
$$

With the above regression equation, the predicted

\begin{tabular}{|c|c|c|c|c|c|}
\hline \multirow[t]{2}{*}{ Formulas $^{1}$} & \multicolumn{2}{|l|}{ Growth cycle (d) } & \multirow[t]{2}{*}{ Formulas } & \multicolumn{2}{|l|}{ Growth cycle (d) } \\
\hline & Measured values ${ }^{2}$ & Predicted values & & Measured values & Predicted values \\
\hline $1(C K)$ & $63.00 \pm 0.0^{\mathrm{a}}$ & 63.00 & 12 & $67.50 \pm 3.10^{\text {cdefg }}$ & 67.50 \\
\hline 2 & $69.14 \pm 2.27^{\mathrm{efg}}$ & 69.14 & 13 & $64.00 \pm 0.00^{\mathrm{ab}}$ & 64.00 \\
\hline 3 & $70.33 \pm 1.29^{9}$ & 70.33 & 14 & $65.13 \pm 2.59^{a b c}$ & 65.13 \\
\hline 4 & $70.00 \pm 0.00^{\mathrm{fg}}$ & 70.00 & 15 & $100.00 \pm 0.00^{i}$ & 100 \\
\hline 5 & $66.40 \pm 3.10^{\text {bcde }}$ & 66.40 & 16 & $66.65 \pm 3.00^{\mathrm{bcd}}$ & 66.65 \\
\hline 6 & $63.58 \pm 0.52^{a b}$ & 63.25 & 17 & $67.30 \pm 3.10^{\text {cdef }}$ & 67.30 \\
\hline 7 & $67.31 \pm 2.59^{\text {cdef }}$ & 67.31 & 18 & $67.76 \pm 3.20^{\text {cdefg }}$ & 67.76 \\
\hline 8 & $70.00 \pm 0.00^{\mathrm{fg}}$ & 70.00 & 19 & $74.46 \pm 3.00^{g h}$ & 74.46 \\
\hline 9 & $66.00 \pm 2.24^{\mathrm{bcd}}$ & 66.00 & 20 & $73.74 \pm 2.90^{g h}$ & 73.74 \\
\hline 10 & $68.33 \pm 4.23^{\mathrm{defg}}$ & 68.33 & 21 & $70.71 \pm 2.80^{g}$ & 70.71 \\
\hline 11 & $64.60 \pm 1.90^{\mathrm{abc}}$ & 64.60 & & & \\
\hline
\end{tabular}
growth cycle can be calculated for each formula, and the measured growth cycle and the predicted growth cycle were basically the same. The statistical analysis showed that the $\mathrm{P}$ values of the mixed linear model and the quadratic regression model were both less than 0.0001 , indicating that these two models both had a very significant level $(\mathrm{P}<0.01)$ and fitted the relation between ingredients and growth cycle well. In addition, the correlation

Table 5 Measured values and predicted values of the growth cycle

${ }^{1}$ Notes are the same as Table 1

${ }^{2}$ Means followed by the same letter are not significantly different at a level of $5 \%(P<0.05)$ 
Table 6 Variance analysis of the quadratic polynomial regression model for the growth cycle

\begin{tabular}{lcrrrrr}
\hline $\begin{array}{l}\text { Variation } \\
\text { sources }\end{array}$ & $\begin{array}{l}\text { Sum } \\
\text { of squares }\end{array}$ & DF & Mean square & F & P \\
\hline Model & 3407.93 & 14 & 243.42 & 71.35 & $<0.0001$ \\
$\begin{array}{l}\text { Linear mixed } \\
\text { model }\end{array}$ & 733.34 & 4 & 183.34 & 53.73 & $<0.0001$ \\
$X_{1} X_{2}^{a}$ & 16.54 & 1 & 16.54 & 4.85 & 0.0342 \\
$X_{1} X_{3}$ & 0.86 & 1 & 0.86 & 0.25 & 0.6178 \\
$X_{1} X_{4}$ & 25.43 & 1 & 25.43 & 7.45 & 0.0097 \\
$X_{1} X_{5}$ & 3.51 & 1 & 3.51 & 1.03 & 0.3173 \\
$X_{2} X_{3}$ & 4.10 & 1 & 4.10 & 1.20 & 0.2805 \\
$X_{2} X_{4}$ & 51.26 & 1 & 51.26 & 15.02 & 0.0004 \\
$X_{2} X_{5}$ & 0.15 & 1 & 0.15 & 0.044 & 0.8344 \\
$X_{3} X_{4}$ & 78.88 & 1 & 78.88 & 23.12 & $<0.0001$ \\
$X_{3} X_{5}$ & 21.72 & 1 & 21.72 & 6.37 & 0.0162 \\
$X_{4} X_{5}$ & 2098.92 & 1 & 2098.92 & 615.18 & $<0.0001$ \\
Residual & 122.83 & 36 & 3.41 & & \\
Lack of fit & 0.00008 & 6 & 0.00001 & 0.000003 & 1.0000 \\
Error & 122.83 & 30 & 4.09 & & \\
Sum & $12,865.92$ & 44 & & & \\
\hline
\end{tabular}

a Notes are the same as Table 1

coefficient $\left(R^{2}=0.9652\right)$ indicated that the equation model had $96.52 \%$ goodness-of-fit with the experimental data (Tables 5 and 6).

The regression equation showed that for the equation coefficients, $K\left(X_{3}\right)=70.33>K\left(X_{4}\right)=70.00>K\left(X_{2}\right)$ $=69.14>K\left(X_{5}\right)=66.40>K\left(X_{1}\right)=63.00$; that is, the degree of contribution of each substrate to the growth cycle is $\mathrm{X}_{3}$ (soybean straw) $>\mathrm{X}_{4}$ ( (rice straw) $>\mathrm{X}_{2}$ (corn cob) $>X_{5}$ (corn straw) $>X_{1}$ (sawdust), indicating that the contribution of crop straw to the growth cycle is greater than that of the sawdust. Correlation in terms of how each substrate impacted the growth cycle analyzed by SPSS software, and the Pearson correlation coefficients between the substrate and the growth cycle were as follows: rice straw $(0.334)>$ corn straw $(0.235)>$ soybean straw $(-0.126)>$ corn cob $(-0.168)>$ sawdust $(0.283)$. Among these, the rice straw and corn straw were both positively correlated with the growth cycle; that is, the rice straw and corn straw could extend the growth cycle of G. frondosa. The growth cycle was negatively correlated with the sawdust, corn cob and soybean straw, indicating that these three types of substrates can shorten the growth cycle of G. frondosa, with sawdust significantly shortening the growth cycle of $G$. frondosa. Details can be seen in Tables 5 and 7.

The equation coefficients of the mixed schemes showed the degree to which the different straw combinations impacted the growth cycle. The results showed that
Table 7 Correlation analysis between the growth cycle and different ingredients

\begin{tabular}{|c|c|c|c|c|c|}
\hline & $X_{1}^{a}$ & $X_{2}^{a}$ & $X_{3}^{a}$ & $\mathrm{X}_{4}^{\mathrm{a}}$ & $X_{5}^{a}$ \\
\hline \multicolumn{6}{|l|}{ Growth cycle ${ }^{b}$} \\
\hline Pearson & $-0.283^{* *}$ & -0.168 & -0.126 & $0.334^{* *}$ & 0.235 \\
\hline Significance & 0.213 & 0.468 & 0.586 & 0.139 & 0.305 \\
\hline$N$ & 21 & 21 & 21 & 21 & 21 \\
\hline
\end{tabular}

$$
\begin{aligned}
K\left(X_{4} X_{5}\right) & =127.20>K\left(X_{1} X_{4}\right)=14.00>K\left(X_{1} X_{5}\right) \\
& =5.20>K\left(X_{1} X_{3}\right)=2.58>K\left(X_{2} X_{5}\right) \\
& =-1.08>K\left(X_{2} X_{3}\right)=-5.62>K\left(X_{1} X_{2}\right) \\
& =-11.29>K\left(X_{3} X_{5}\right)=-12.94>K\left(X_{2} X_{4}\right) \\
& =-19.88>K\left(X_{3} X_{4}\right)=-24.66 .
\end{aligned}
$$

The degree of contribution was $\mathrm{X}_{4} \mathrm{X}_{5}$ (rice straw and corn straw) $>\mathrm{X}_{1} \mathrm{X}_{4}$ (sawdust and rice straw) $>\mathrm{X}_{1} \mathrm{X}_{5}$ (sawdust and corn straw) $\mathrm{X}_{1} \mathrm{X}_{3}$ (sawdust and soybean straw) $>X_{2} X_{5}$ (corn cob and corn straw) $>X_{2} X_{3}$ (corn cob and soybean straw) $>X_{1} X_{2}$ (sawdust and corn cob) $>X_{3} X_{5}$ (soybean straw and corn straw) $>\mathrm{X}_{2} \mathrm{X}_{4}$ (corn cob and rice straw) $>\mathrm{X}_{3} \mathrm{X}_{4}$ (soybean straw and rice straw). When combined with the interaction analysis, the results showed that mixing rice straw with the sawdust, corn cob, soybean straw or corn straw could significantly increase the growth cycle, and the life cycle increased with the increase of rice straw (Table 5).

\section{High-yielding formula and verification test}

Using the yield as the evaluation index and setting the variation range and expected response value of each ingredient, steepest slope prediction was carried out based on the regression equation beginning from a random combination, and a high-yielding formula with no sawdust was generated. The formula was as follows: corn $\operatorname{cob}\left(\mathrm{X}_{2}\right) 97.5 \%$ and rice straw $\left(\mathrm{X}_{4}\right) 2.5 \%$, which were multiplied by the coefficient of 0.75 and converted to $73.125 \%$ corn cob and $1.875 \%$ rice straw, respectively, combined with $23 \%$ wheat bran and $2 \%$ light $\mathrm{CaCO}_{3}(\mathrm{C} / \mathrm{N}=48.40)$. The predicted yield was $134.07 \mathrm{~g} / \mathrm{bag}$. The measured yield of the first flush reached $134.72 \pm 4.24 \mathrm{~g} / \mathrm{bag}$, which basically verified the predicted fitted value. The results showed that the formula had a yield $39.97 \%$ higher than the control, with a $\mathrm{BE}$ of $44.91 \pm 1.41 \%$. In addition to yield and $\mathrm{BE}$, single-fruiting-body length and width, the growth cycle of the high-yielding formula was also 
Table 8 Comparison of the main agronomic traits between the high-yield straw-substrate formula and the control

\begin{tabular}{|c|c|c|c|c|c|c|c|}
\hline \multirow[t]{2}{*}{ Formulas } & \multirow{2}{*}{$\begin{array}{l}\text { Single-fruiting-body } \\
\text { length }(\mathrm{cm})^{2}\end{array}$} & \multirow{2}{*}{$\begin{array}{l}\text { Single-fruiting-body } \\
\text { width }(\mathrm{cm})\end{array}$} & \multicolumn{2}{|l|}{ Yield (g) } & \multicolumn{2}{|l|}{ Growth cycle (d) } & \multirow[t]{2}{*}{$\mathrm{BE}(\%)$} \\
\hline & & & Predicted value & Measured value & Predicted value & Measured value & \\
\hline $1(\mathrm{CK})$ & $2.58 \pm 0.37^{b}$ & $2.34 \pm 0.37^{b}$ & 96.97 & $97.25 \pm 9.71^{b}$ & 63.00 & $63.00 \pm 0.0^{\mathrm{a}}$ & $32.42 \pm 3.24^{b}$ \\
\hline $\mathrm{Hy}^{1}$ & $5.15 \pm 0.148^{\mathrm{a}}$ & $3.45 \pm 0.24^{\mathrm{a}}$ & 134.07 & $134.72 \pm 4.24^{\mathrm{a}}$ & 68.68 & $68.68 \pm 2.32^{b}$ & $44.91 \pm 1.41^{\mathrm{a}}$ \\
\hline
\end{tabular}

${ }^{1}$ Hy high-yield

${ }^{2}$ Mean values followed by no letters are not significantly different at a level of $5 \%(P<0.05)$

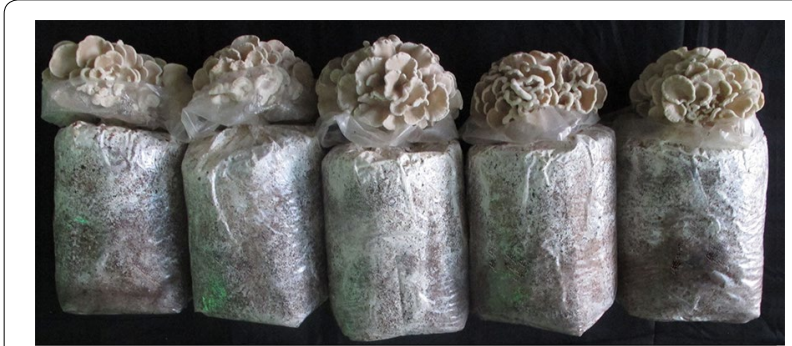

CK

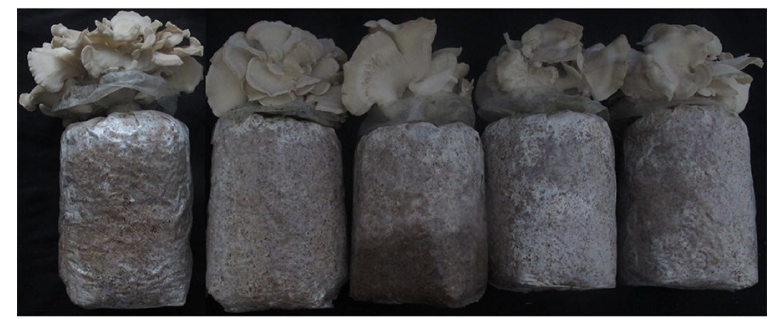

Hy

Fig. 1 Grifola frondosa fruiting in the high-yield formula (Hy) and the control (CK)

examined. The single-fruiting-body length and width of G. frondosa for the high-yield (5.15 and 3.45 respectively) formula were higher than those for the control (2.58 and 2.34 respectively), but the growth cycle was longer than that of the control (Table 8 and Fig. 1).

\section{Discussion}

Interest in G. frondosa production has increased significantly in the last decade due to their nutritional and health-promoting benefits (Vetvicka and Vetvickova 2014; Ding et al. 2016). G. frondosa is traditionally cultivated on forest wood (sawdust) however due to recent efforts in managing forest resources the use of agro-forestry products for its cultivation is not sustainable. Most edible fungi can be cultivated with agro-residues such as crop straws (Barreto et al. 2008; Philippoussis 2009) either by composting or non-composting. However, due to the differences in nutritional requirements, growth specificity, inheritance characteristics and activities of the secreted extracellular enzymes among edible fungi (Montoya et al. 2012; Yang et al. 2013a), differences exist in the utilization capacity of the different crop straws. In this work, we investigated the use of different crop straw (corn cob, soybean straw, rice straw and corn stalk) as alternate substrate to sawdust for cultivating G. frondosa and developed a statistical model for optimizing production and evaluated its effect on yield and growth cycle.

In our work, all substrate formulae contained 23\% wheat bran and $2 \%$ light $\mathrm{CaCO}_{3}$. Substrates supplemented with wheat bran produces better quality mushrooms (Moonmoon et al. 2011) while the limited amount of $\mathrm{CaCO}_{3}$ improves calcium metabolism, adjust $\mathrm{pH}$ of substrates and makes mushroom production more consistent from crop to crop (Royse and Sanchez-Vazquez 2003).

This study showed that in optimizing the formula of $G$. frondosa production, the yield could be increased by adding a certain proportion of corn cob $(50 \%)$, such as used in formula 6, which had a yield of $22.37 \%$ higher than the control. The use of rice straw negatively correlated with yield; however, it can still be increased by the addition of a certain proportion (50\%) of corn cob to rice straw, such as used in formula 11. For instance, formula 11 $(110.00 \pm 11.41 \mathrm{~g})$ showed a yield increase of $246.45 \%$ compared with formula $4(31.75 \pm 3.61 \mathrm{~g})$, which had rice straw alone, and showed a yield increase of $13.72 \%$ compared with the control group (Table 2). Therefore, in places where the rice resources are rich, adding an appropriate proportion of corn cob to replace sawdust can achieve the same effect in G. frondosa cultivation. Soybean straw and corn straw in a reasonable mixture ratio, or combined with substrates such as corn cob, can also replace sawdust to achieve the same effect in cultivation. When the yield is considered the priority indicator in the production of $G$. frondosa, using corn cob powder as the main cultivation substrate substitute for sawdust will not only increase the yield but also increase the single-fruiting-body area.

When the growth cycle is used as the sole evaluation index, sawdust, soybean straw and corn cob can significantly shorten the growth cycle of G. frondosa, with sawdust having the greatest effect. For instance, with formula 6, which had $37.5 \%$ sawdust and $37.5 \%$ corn cob, the growth cycle was nearly the same as that 
in control, and its yield was higher than that in control. Although G. frondosa had a long growth cycle with the soybean straw substrate, the growth cycle can be significantly shortened by combining soybean straw with rice straw and corn straw, as evidenced in formulae 13 and 14 (Table 5). Therefore, when taking both growth cycle and yield into account, a certain percentage of sawdust can be added to the straw formula to shorten the growth cycle and increase the yield of G. frondosa as well. Since lignin content in sawdust was higher than that in crop straws, the substrate with high lignin content is observed to promote mycelial growth and thus shorten the growth cycle. The rapid colonization of substrate during spawn run prevents competition from other competitive molds and pathogenic microorganisms. Also, the shortened duration of the growth cycle saves costs, improve income and it is suitable for commercial producers of $G$. frondosa (Gaitan-Hernandez et al. 2006).

The effects of different ingredients on the agronomic traits of G. frondosa were different. This can be attributed to their nutrient composition and structure of the different ingredient. The materials used in the cultivation medium, such as sawdust, corn cob and cottonseed shell are composed of lignin, cellulose and minerals, which provides sufficient carbon and nitrogen sources for the growth and development of edible fungi (Naraian et al. 2009). In accordance with the production needs, these ingredients can be mixed to achieve the desired goal of cultivation. The $\mathrm{C} / \mathrm{N}$ ratio as an index must be considered in the choice of raw materials to include substrate formulation because it plays a vital role in the growth of edible fungi.

The study showed that substrates with low carbonnitrogen ratios result in significant reduction in the yield of Grifola frondosa, observed with formulae 3-5, 13, 15, and 18-21. Also higher carbon and nitrogen ratios did not improve $G$. frondosa yield, as with the use of sawdust in formula 1. However, some of the low carbon-nitrogen formulations yield higher than control, such as formula $10(\mathrm{C} / \mathrm{N}=28.65)$ and the formula 14 $(\mathrm{C} / \mathrm{N}=25.22)$. A high carbon-nitrogen ratio is beneficial to the growth of mycelia, and thus shortens the growth period of $G$. frondosa, as in formulae $1(\mathrm{C} / \mathrm{N}=74.64)$ and $6(\mathrm{C} / \mathrm{N}=59.81)$, the shortest growth period, of 63 and 63.58 days respectively (Tables 1,5 ). Low carbon and nitrogen sources leads to premature senescence and slow mycelial growth respectively. On the other hand, high nitrogen levels lead to vigorous mycelial growths resulting in the accumulation of unwanted metabolic products, which affected the yield (Naraian et al. 2009; Hoa et al. 2015). These findings were consistent to the results reported by Naraian (Naraian et al. 2009). Therefore a reasonable $\mathrm{C} / \mathrm{N}$ ratio plays a crucial role in the yield and growth cycle of edible fungi (Naraian et al. 2009; Hoa et al. 2015).

The results of this study can be directly applied in the industrial production of $G$. frondosa, which is more suitable for the developmental requirements of the edible fungi industry. However, formulae and techniques need to be optimized, and the economic balance needs to be improved before commercial development is achieved (Gaitan-Hernandez et al. 2006). Hence, the need to use a statistical method to optimize and standardize substrate mixtures for optimal growth and yield.

The use of the simplex-lattice method for formula design has been less applied in the field of edible fungi (Yang et al. 2016). However, as the most basic design scheme in the mixture design, this method is widely used in feed, medicine and food industries because the test points can be taken on the lattice points in the regular simplex to ensure that the test points are evenly distributed and that the calculation is simple and accurate since the regression coefficient is only a simple function of the response values at the corresponding lattice points. In this study, by using the simplex-lattice design, the purpose of testing the effects of different mixture ratios of crop straws and sawdust on the cultivation of $G$. frondosa was achieved; this was affirmed by the high $\mathrm{R}^{2}$ value (0.956), indicating the percentage of the variability explained by the model (Table 1 ). In all cases the $\mathrm{R}^{2}$ was higher than 0.8 , with values over $\sim 0.9$ in almost all responses.

Consequently, the optimized formula obtained was effective, and the yield and growth cycle equations allow effective prediction of the production effect of the formula. Therefore, the simplex-lattice design can be applied designing experiments for the formulation of substrates for edible fungi cultivation.

Our results show that corn cob was the best alternative to sawdust as a substrate for producing a high yield of $G$. frondosa. This is because corn cob does not only provide nutrients for the growth but as a substrate, it supports and facilitates the attachment of the fungi and allows oxygen transfer, heat dispersion and has the suitable $\mathrm{C} / \mathrm{N}$ ratio to promote the induction of fruiting bodies among other conditions (Hoa et al. 2015; Pérez-Rodríguez et al. 2016). Compared to rice straw, corn cob has high lignin content, certain proportions of soluble polysaccharides, which can be directly utilized by the mycelia, and it is beneficial to the growth of edible fungi.

Corn cob was considered the best agricultural residue among all the other common studied wastes (Naraian et al. 2009). Because corn is widely grown in the world, the corn cob is abundant, readily available and cheap, a notable percentage makes up the by-product of maize processing (Niu et al. 2016) and has been widely used in 
industry and agriculture. Its composition indicates the potential utilization as substrate for fungal growth as well as the production of industrial enzymes such as xylanase and xylose among others (Amaro-Reyes et al. 2016; Kashid and Ghosalkar 2017).

In conclusion, corn cob significantly increases the yield of G. frondosa and can replace sawdust as the main cultivation substrate of $G$. frondosa, but sawdust significantly shortens the growth cycle of G. frondosa. The optimized high-yield formula was $73.125 \%$ corn cob, $1.875 \%$ rice straw, $23 \%$ wheat bran, and $2 \%$ light $\mathrm{CaCO}_{3}$ $(\mathrm{C} / \mathrm{N}=48.40)$; the average yield of the first flush was $134.72 \pm 4.24 \mathrm{~g} / \mathrm{bag}$, and the BE was $44.91 \pm 1.41 \%$. The results of this study reinforce the use of crop straw for cultivation of $G$. frondosa and provide a scientific basis for the production of $G$. frondosa using corn cob as the main substrate.

\section{Abbreviations}

ANOVA: one-way analysis of variance; BE: biological efficiency; $\mathrm{C} / \mathrm{N}$ : carbon to nitrogen ratio; SPSS: statistical product and service solutions.

\begin{abstract}
Authors' contributions
BS, JQY and FLS conceived and designed the experiments, performed the experiments, analyzed the data, wrote the paper, prepared figures and/or tables, these authors contributed equally to this work; CTL and DL conceived and designed the experiments; LSM and SX performed the experiments; YPF and YL conceived and designed the experiments, analyzed the data, contributed reagents/materials/analysis tools, wrote the paper, prepared figures and/ or tables, reviewed drafts of the paper. All authors read and approved the final manuscript.
\end{abstract}

\section{Author details}

${ }^{1}$ Engineering Research Centre of Chinese Ministry of Education for Edible and Medicinal Fungi, Jilin Agricultural University, Changchun 130118, People's Republic of China. ${ }^{2}$ Microbiology Research Institute, Guangxi Academy of Agricultural Sciences, Nanning 530007, Guangxi, People's Republic of China.

\section{Acknowledgements}

We thank David Hawksworth and Odeshnee Moodley for their kind-hearted and excellent technical assistance with the English language correction.

\section{Competing interests}

The authors declare that they have no competing interests.

\section{Availability of data and materials}

The datasets supporting the conclusions of this article are included within the article.

\section{Ethics approval and consent to participate}

This article does not contain studies with human participants or animals performed by any of the authors.

\section{Funding}

This work was supported by the Special Fund for Agro-scientific Research in the Public Interest (No. 201503137), National Key Research and Development Program of China (No. 2017YFD0601002), the program of creation and utilization of germplasm of mushroom crop of "111" project (No. D17014), National Basic Research Program of China (No. 2014CB138305), University S \& T Innovation Platform of Jilin Province for Economic Fungi (No. \#2014B-1) and National Natural Science Foundation of China (No. 31471926).

\section{Publisher's Note}

Springer Nature remains neutral with regard to jurisdictional claims in published maps and institutional affiliations.

Received: 18 January 2018 Accepted: 3 March 2018

Published online: 23 March 2018

\section{References}

Ainsworth GC, Bisby GR, Kirk PM (2008) Ainsworth and Bisby's dictionary of the fungi, 10th edn. CABI Bioscience, Wallingford

Amaro-Reyes A, Gracida J, Huizache-Pena N, Elizondo-Garcia N, SalazarMartinez J, Garcia Almendarez BE, Regalado C (2016) On-site hydrolytic enzymes production from fungal co-cultivation of Bermuda grass and corn cob. Biores Technol 212:334-337. https://doi.org/10.1016/j. biortech.2016.04.070

Barreto S, López M, Levin L (2008) Effect of culture parameters on the production of the edible mushroom Grifola frondosa (maitake) in tropical weathers. World J Microbiol Biotechnol 24(8):1361-1366

Ding Y, Xiao C, Wu Q, Xie Y, Li X, Hu H, Li L (2016) The mechanisms underlying the hypolipidaemic effects of Grifola frondosa in the liver of rats. Front Microbiol 7:1186. https://doi.org/10.3389/fmicb.2016.01186

Gaitan-Hernandez R, Esqueda M, Gutierrez A, Sanchez A, Beltran-Garcia M, Mata G (2006) Bioconversion of agrowastes by Lentinula edodes: the high potential of viticulture residues. Appl Microbiol Biotechnol 71(4):432-439. https://doi.org/10.1007/s00253-005-0241-1

Gregori A, Svagelj M, Berovic M, Liu Y, Zhang J, Pohleven F, Klinar D (2009) Cultivation and bioactivity assessment of Grifola frondosa fruiting bodies on olive oil press cakes substrates. New Biotechnol 26(5):260-262. https:// doi.org/10.1016/j.nbt.2009.08.001

Gu CQ, Li JW, Chao F, Jin M, Wang XW, Shen ZQ (2007) Isolation, identification and function of a novel anti-HSV-1 protein from Grifola frondosa. Antiviral Res 75(3):250-257. https://doi.org/10.1016/j.antiviral.2007.03.011

Hoa HT, Wang CL, Wang CH (2015) The effects of different substrates on the growth, yield, and nutritional composition of two oyster mushrooms (Pleurotus ostreatus and Pleurotus cystidiosus). Mycobiology 43(4):423-434. https://doi.org/10.5941/MYCO.2015.43.4.423

Hu Y, Wang LS, Li Y, Li QH, Li CL, Chen JM, Weng D, Li HP (2017) Effects of particulate matter from straw burning on lung fibrosis in mice. Environ Toxicol Pharmacol 56:249-258. https://doi.org/10.1016/j.etap.2017.10.001

Illana-Esteban C (2008) The fungus maitake (Grifola frondosa) and its therapeutic potential. Revista iberoamericana de micologia 25(3):141-144

Kashid M, Ghosalkar A (2017) Evaluation of fermentation kinetics of acidtreated corn cob hydrolysate for xylose fermentation in the presence of acetic acid by Pichia stipitis. 3 Biotech 7(4):240. https://doi.org/10.1007/ s13205-017-0873-8

Kraisit P, Limmatvapirat S, Nunthanid J, Sriamornsak P, Luangtana-Anan M (2017) Preparation and characterization of hydroxypropyl methylcellulose/polycarbophil mucoadhesive blend films using a mixture design approach. Chem Pharm Bull 65(3):284-294. https://doi.org/10.1248/cpb. c16-00849

Lin CH, Chang CY, Lee KR, Lin HJ, Lin WC, Chen TH, Wan L (2016) Cold-water extracts of Grifola frondosa and its purified active fraction inhibit hepatocellular carcinoma in vitro and in vivo. Exp Biol Med (Maywood) 241(13):1374-1385. https://doi.org/10.1177/1535370216640149

Lundstedt T, Seifert E, Abramo L, Thelin B, Nyström Å, Pettersen J, Bergman $\mathrm{R}$ (1998) Experimental design and optimization. Chemometr Intell Lab 42(1-2):3-40

Mayell M (2001) Maitake extracts and their therapeutic potential. Altern Med Rev J Clin Ther 6(1):48-60

Montoya S, Orrego CE, Levin L (2012) Growth, fruiting and lignocellulolytic enzyme production by the edible mushroom Grifola frondosa (maitake). World J Microbiol Biotechnol 28(4):1533-1541. https://doi.org/10.1007/ s11274-011-0957-2

Moonmoon M, Uddin MN, Ahmed S, Shelly NJ, Khan MA (2010) Cultivation of different strains of king oyster mushroom (Pleurotus eryngii) on saw dust and rice straw in Bangladesh. Saudi J Biol Sci 17(4):341-345. https://doi. org/10.1016/j.sjbs.2010.05.004 
Moonmoon M, Shelly NJ, Khan MA, Uddin MN, Hossain K, Tania M, Ahmed $S$ (2011) Effects of different levels of wheat bran, rice bran and maize powder supplementation with saw dust on the production of shiitake mushroom (Lentinus edodes (Berk.) Singer). Saudi J Biol Sci 18(4):323-328. https://doi.org/10.1016/j.sjbs.2010.12.008

Naraian R, Sahu R, Kumar S, Garg S, Singh C, Kanaujia R (2009) Influence of different nitrogen rich supplements during cultivation of Pleurotus florida on corn cob substrate. Environmentalist 29:1-7

Niu WJ, Han LJ, Liu X, Huang GQ, Chen LJ, Xiao WH, Yang ZL (2016) Twenty-two compositional characterizations and theoretical energy potentials of extensively diversified China's crop residues. Energy 100(1):238-250

Park HS, Hwang YH, Kim MK, Hong GE, Lee HJ, Nagappan A, Yumnam S, Kim EH, Heo JD, Lee SJ, Won CK, Kim GS (2015) Functional polysaccharides from Grifola frondosa aqueous extract inhibit atopic dermatitis-like skin lesions in NC/Nga mice. Biosci Biotechnol Biochem 79(1):147-154. https://doi.org/10.1080/09168451.2014.963500

Pedri ZC, Lozano LM, Hermann KL, Helm CV, Peralta RM, Tavares LB (2015) Influence of nitrogen sources on the enzymatic activity and grown by Lentinula edodes in biomass Eucalyptus benthamii. Braz J Biol Revista brasleira de biologia 75(4):940-947. https://doi.org/10.1590/1519-6984.03214

Pérez-Rodríguez N, Torrado-Agrasar A and Domínguez J M (2016) Use of Aspergillus niger Extracts Obtained by Solid-State Fermentation In: Mushroom Biotechnology pp.173-190. https://doi.org/10.1016/ B978-0-12-802794-3.00010-2

Philippoussis A (2009) Production of mushrooms using agro-industrial residues as substrates. Springer, Northern Ireland

Pires FQ, Angelo T, Silva JK, Sa-Barreto LC, Lima EM, Gelfuso GM, Gratieri T, Cunha-Filho MS (2017) Use of mixture design in drug-excipient compatibility determinations: thymol nanoparticles case study. J Pharm Biomed Anal 137:196-203. https://doi.org/10.1016/j.jpba.2017.01.037

Royse DJ, Sanchez-Vazquez JE (2003) Influence of precipitated calcium carbonate ( $\mathrm{CaCO} 3)$ on shiitake (Lentinula edodes) yield and mushroom size. Biores Technol 90(2):225-228

Saoudi S, Chammem N, Sifaoui I, Jimenez IA, Lorenzo-Morales J, Pinero JE, Bouassida-Beji M, Hamdi M, L Bazzocchi I (2017) Combined effect of carnosol, rosmarinic acid and thymol on the oxidative stability of soybean oil using a simplex centroid mixture design. J Sci Food Agric 97(10):33003311. https://doi.org/10.1002/jsfa.8179

Scheffé H (1963) The simplex-centroid design for experiments with mixtures. J R Stat Soc Series B Stat Methodol 25(B):235-263
Shen Q, Royse DJ (2001) Effects of nutrient supplements on biological efficiency, quality and crop cycle time of maitake (Grifola frondosa). Appl Microbiol Biotechnol 57(1-2):74-78

Shin YJ, Lee SC (2014) Antioxidant activity and $\beta$-glucan contents of hydrothermal extracts from maitake (Grifola frondosa). Food Sci Biotechnol 23(1):277-282

Teng B, Zhang X, Yi C, Zhang Y, Ye S, Wang Y, Tong DQ, Lu B (2017) The association between ambient air pollution and allergic rhinitis: further epidemiological evidence from changchun, northeastern china. Int J Environ Res Public Health 14(3):1-18

Verma P, Rastogi RK, Ramakumar KL (2007) Determination of trace amounts of nitrogen in uranium based samples by ion chromatography (IC) without Kjeldahl distillation. Anal Chim Acta 596(2):281-284. https://doi. org/10.1016/j.aca.2007.06.019

Vetvicka V, Vetvickova J (2014) Immune-enhancing effects of Maitake (Grifola frondosa) and Shiitake (Lentinula edodes) extracts. Ann Transl Med 2(2):14. https://doi.org/10.3978/j.issn.2305-5839.2014.01.05

Wang H, Yuan S, Zhan J, Wang Y, Yu G, Deng S, Huang J, Wang B (2015) Mechanisms of enhanced total organic carbon elimination from oxalic acid solutions by electro-peroxone process. Water Res 80:20-29. https://doi. org/10.1016/j.watres.2015.05.024

Yang B, Chen Z, Zhang C, Dong J, Peng X (2012) Distribution patterns and major sources of dioxins in soils of the Changsha-Zhuzhou-Xiangtan urban agglomeration, China. Ecotoxicol Environ Saf 84:63-69. https://doi. org/10.1016/j.ecoenv.2012.06.021

Yang L, Qu H, Mao G, Zhao T, Li F, Zhu B, Zhang B, Wu X (2013a) Optimization of subcritical water extraction of polysaccharides from Grifola frondosa using response surface methodology. Pharm Mag 9(34):120-129. https:// doi.org/10.4103/0973-1296.111262

Yang W, Guo F, Wan Z (2013b) Yield and size of oyster mushroom grown on rice/wheat straw basal substrate supplemented with cotton seed hull. Saudi J Biol Sci 20(4):333-338. https://doi.org/10.1016/j.sjbs.2013.02.006

Yang J, Zhang G, Yang Q, Hu J (2016) Biology research of Pleurotus ostreatus cultivated in differnet raw material. J Northwest For Univ (China) 31(3):170-174

\section{Submit your manuscript to a SpringerOpen ${ }^{\circ}$ journal and benefit from:}

- Convenient online submission

- Rigorous peer review

- Open access: articles freely available online

- High visibility within the field

- Retaining the copyright to your article

Submit your next manuscript at $\boldsymbol{\nabla}$ springeropen.com 